(2) Open Access Full Text Article

REVIEW

\title{
Immune Regulation of the cGAS-STING Signaling Pathway in the Tumor Microenvironment and Its Clinical Application
}

This article was published in the following Dove Press journal: OncoTargets and Therapy

\author{
Feifei Pu $\mathbb{1}^{1, *}$ \\ Fengxia Chen ${ }^{2, *}$ \\ Jianxiang Liu' \\ Zhicai Zhang' \\ Zengwu Shao' \\ 'Department of Orthopedics, Union \\ Hospital, Tongji Medical College, \\ Huazhong University of Science and \\ Technology, Wuhan, People's Republic of \\ China; ${ }^{2}$ Department of Radiation and \\ Medical Oncology, Zhongnan Hospital, \\ Wuhan University, Wuhan, People's \\ Republic of China
}

*These authors contributed equally to this work
Correspondence: Zengwu Shao Department of Orthopedics, Union Hospital, Tongii Medical College,

Huazhong University of Science and Technology, 1277 jiefang Avenue, Wuhan, 430022, Hubei, People's Republic of China $\mathrm{Tel} / \mathrm{Fax}+862785351626$

Email 1985XH0536@hust.edu.cn

\begin{abstract}
As a DNA receptor in the cytoplasm, cyclic GMP-AMP synthase (cGAS) contributes to the recognition of abnormal DNA in the cytoplasm and contributes to the stimulator of interferon genes (STING) signaling pathway. cGAS could mediate the expression of interferon-related genes, inflammatory-related factors, and downstream chemokines, thus initiating the immune response. The STING protein is a key effector downstream of the DNA receptor pathway. It is widely expressed across cell types such as immune cells, tumor cells, and stromal cells and plays a role in signal transduction for cytoplasmic DNA sensing and immunity. STING agonists, as novel agonists, are used in preclinical research and in the treatment of various tumors via clinical trials and have displayed attractive application prospects. Studying the cGAS-STING signaling pathway will deepen our understanding of tumor immunity and provide a basis for the research and development of antitumor drugs.

Keywords: cGAS, STING, innate immunity, tumor, immunotherapy, drug discovery
\end{abstract}

\section{Introduction}

There exists a relationship between a tumor and the immune system, and the latter selectively recognizes and kills tumor cells through immune surveillance. ${ }^{1}$ Consequently, tumor cells have evolved mechanisms to bypass this process, hijacking the immune system to promote tumor formation. ${ }^{2,3}$ Therefore, the dual regulation of the immune system in inhibiting and promoting tumorigenesis poses great challenges to treatment prospects. Cyclic GMP-AMP synthase (cGAS) is a cytoplasmic DNA pattern recognition receptor that has been widely studied in recent years. It regulates downstream immune responses by sensing abnormal DNA in the cytoplasm and plays a dual role in tumor development. ${ }^{4}$

Oxidative stress, metabolic changes, and genetic instability lead to DNA damage in the nucleus and mitochondria, releasing DNA into the cytoplasm. Tumor-derived DNA or cyclic GMP-AMP (cGAMP) is considered to enter dendritic cells (DCs) through gap junctions or via endocytosis. ${ }^{5-7}$ Subsequently, the stimulator of interferon genes (STING) signaling pathway is stimulated, contributing to cell surface co-stimulator molecule expression. Furthermore, it promotes DC maturation and enhances DC antigen presentation. ${ }^{8}$ STING is also expressed in immune cells, such as macrophages, T cells, and natural killer (NK) cells; tumor cells; and stromal cells. ${ }^{9}$ This means that tumor cell-derived cGAMP activates the STING signaling pathway of DCs and of other cells in the tumor microenvironment, differentially regulating immunity. 
Therefore, studying immune regulation by STING signaling pathway activation in the tumor microenvironment and STING agonists is essential for successful tumor therapy.

\section{Innate Immunity of Tumors}

After numerous tumor cell proliferative cycles, daughter cell protein and gene expression is altered, allowing tumor cells to evade the immune response of the body and reducing their susceptibility to antitumor drugs. ${ }^{10}$ Simultaneously, these changes lead to an inefficient host immune response against tumor cells. ${ }^{11}$ Enhancing the innate immune response to remove tumor cells will greatly reduce the adverse reactions caused by chemotherapy and radiotherapy. ${ }^{12}$ Cytokines, including interleukin-6 (IL-6), IL-10, tumor necrosis factor- $\alpha$ (TNF- $\alpha$ ), and transforming growth factor- $\beta$ (TGF- $\beta$ ), regulate immune evasion, angiogenesis, and epithelial-mesenchymal transition in the late phase of tumor growth and metastasis. ${ }^{13,14}$ These processes are affected by type interferon (IFN), signal transducer and activator of transcription 3 (STAT3), interferon regulatory factor 3 (IRF3), IRF7, and nuclear factor- $\mathrm{kB}$ (NF-kB). In particular, type I IFN is the most important factor. ${ }^{15}$ Tumor metastasis could be driven by some cytokines, and the loss of host type I IFN signaling accelerates metastasis and impairs NK-cell antitumor function in multiple models of breast cancer. ${ }^{16}$ Studies show that STING is an important upstream regulator of type I IFN; this includes type I IFN induced by IRF3 and NF- $\mathrm{kB}$ nuclear transfer signal transduction. Ultimately, STING facilitates the expression of interferon stimulating gene in tumor cells and adjacent cells. ${ }^{17}$ Although various intracellular DNA receptors have been discovered, studies show that cGAS is a major, indispensable sensor for double-stranded DNA (dsDNA) in the cytoplasm. ${ }^{18}$ Upon recognition by cGAS activation, ATP and GTP are catalyzed to cGAMP to activate STING. Subsequently, STING promotes type I IFN expression, regulating innate immunity. ${ }^{19}$ Downstream STING-TBK1-IRF3 is transduced through protein-protein interactions, and the cGAS-STING signaling pathway is transduced through the transduction of the second messenger such as cGAMP and G-proteincoupled receptor (GPCR), which were catalyzed by cGAS and then directly transmitted to STING. ${ }^{20}$ Moreover, cGAMP is not limited to the intrinsic cellular signal transduction mode and can generate a broader regional immune response through gap junction-mediated signal transduction. ${ }^{21}$

\section{cGAS-STING Signaling Pathway}

Human cGAS is composed of 522 amino acids (aa) with a molecular weight of $60 \mathrm{kD}$. The $130-155$ aa at the $\mathrm{N}$-terminal is a non-conservative sequence with unclear functions; however, 155-522 aa constitutes the C-terminal nucleic acid transferase domain of cGAS, containing a catalytic region located in the center and cationic surface regions dispersed on both sides. ${ }^{22}$ Through the above regions, cGAS combines with the sugar-phosphate backbone in dsDNA to form a polymer in a ratio of one to one. Additionally, the zinc finger region on cGAS further stabilizes its binding to DNA by ionic bonding. ${ }^{23}$ DNA binding induces structural rearrangement of the cGAS nucleic acid transferase catalytic region, forming $2^{\prime}-5^{\prime}$ and $3^{\prime}-5^{\prime}$ cyclic GMP-AMP $\left(2^{\prime}, 3^{\prime}\right.$-cGAMP) with adenosine triphosphate (ATP) and guanosine triphosphate (GTP) as substrates. ${ }^{22}$

After $2^{\prime}, 3^{\prime}$-cGAMP binds to the downstream receptor, STING, signal transmission can be completed. ${ }^{20,24}$ Human STING consists of 379 aa, including the 1-137 aa N-terminal transmembrane domain (NTD), 138-340 aa cyclic dinucleotide-binding domain (CBD), and 341-379 aa C-terminal tail (CTT) ${ }^{25}$ In the resting state, STING protein exists as a homologous dimer, and the NTD of the two molecules are interlocked, anchoring the protein in the endoplasmic reticulum. CBD areas form V-shaped pockets in the cytoplasm for the recognition of $2^{\prime}, 3^{\prime}$-cGAMP. The binding of $2^{\prime}, 3^{\prime}$-cGAMP further induces spatial conformation transformation of STING from a V-shaped to a u-shaped pocket, and the hat structure formed at the opening of the top of the pocket promotes STING dimers to form tetramers and poly complexes. ${ }^{22}$ Poly-aggregated STING is transferred from the endoplasmic reticulum to the Golgi body, recruiting TANK-binding kinase 1 (TBK1) in this process via its CTT region. Autophosphorylation occurs after the binding of TBK1 to the STING polyaggregate (phosphorylation of serine 172, S172), which then activates its kinase activity, and further phosphorylation of STING protein is catalyzed (phosphorylation of serine 366, S366). Phosphorylated STING recruits IRF3 via its CTT region, promoting IRF3 phosphorylation (phosphorylation of serine 396, S396) and dimerization in the nucleus, subsequently activating type I IFN-related gene expression. ${ }^{26,27}$ Meanwhile, STING signals TNF receptor associated factor 6 (TRAF6) and activates the $\mathrm{NF}-\kappa \mathrm{B}$ signaling pathway, further inducing the release of inflammatory factors such as TNF- $\alpha$ and IL- $6 .{ }^{28}$ 
In general, exogenous and endogenous DNA activate cGAS to generate second messenger 2', $3^{\prime}$-cGAMP. After 2', $3^{\prime}$ cGAMP binds to the downstream receptor protein STING, STING transfers to golgi body and polymerization occurs, and then, TBK1, IRF3 and NF- $\mathrm{kB}$ were recruited. This promotes the phosphorylation of IRF3 and NF- $\mathrm{KB}$ and facilitates their entry into the nucleus, finally, the transcription of genes associated with inflammatory factors is activated (Figure 1).

\section{Role of cGAS-STING Signaling Pathway in Tumors Promote Tumor Development}

Activation of the cGAS-STING pathway promotes tumor development. Chronic stimulation of the cGAS-STING pathway may lead to inflammation-driven tumorigenesis. ${ }^{29}$ For example, 7,12-dimethylbenz(a)anthracene (DMBA) is a carcinogen that causes nucleosome release into the cytoplasm and triggers the activation of STING, promoting the development of skin tumors in mice. However, mice with STING deficiency are resistant to DMBA-induced skin cancer. ${ }^{30}$ A recent study reported that the DNA repair function of PARP1 was impeded by the interaction between cGAS and PARP1, and cGAS could respond to DNA damage in lung cancer models. These resulting in genomic instability, inducing malignant transformation, stimulating proliferation in vitro, and accelerating the growth of lung cancer cells in vivo. ${ }^{31}$ By studying the role and mechanism of STING in the development of Lewis lung cancer (LLC), abnormally high expression of STING was found to significantly promote the growth and proliferation of LLC. ${ }^{32}$ These studies show that

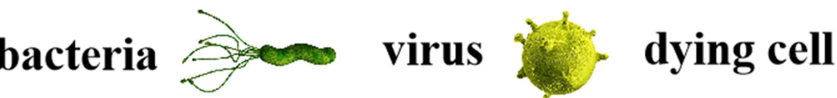 tumour cell

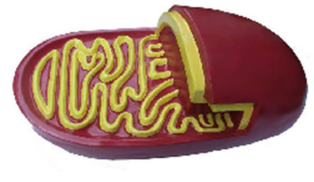

\section{$\Rightarrow$ MOIDDSTIOII dsDNA}

mitochondria
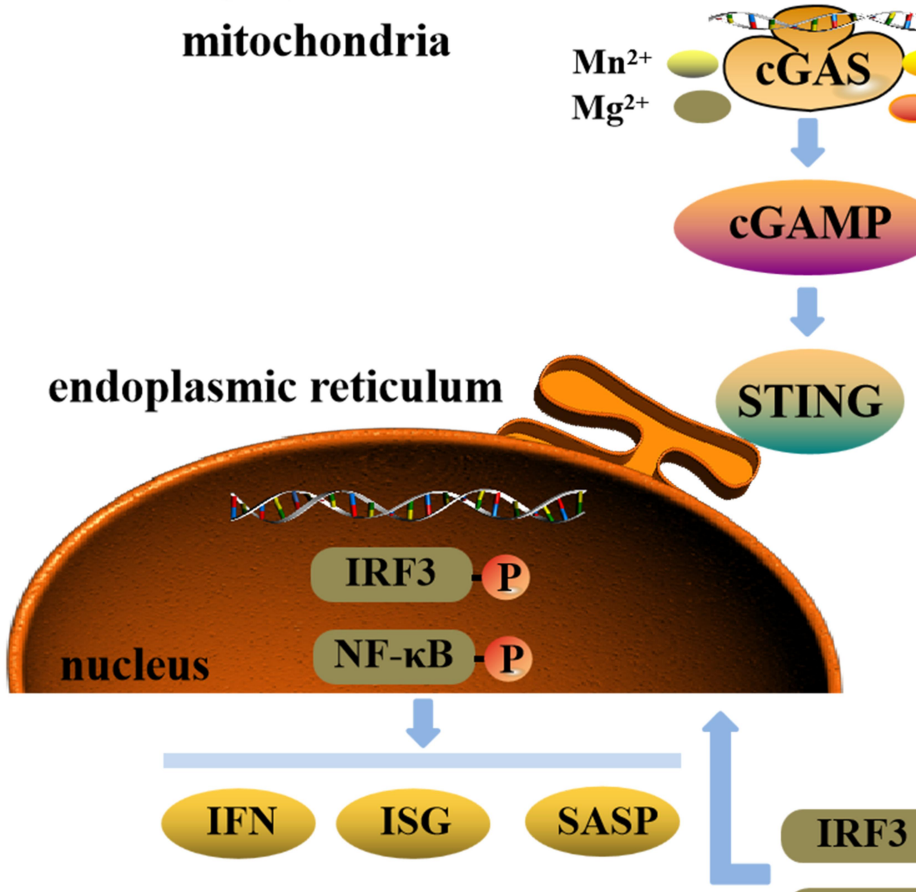

\section{IRF3}

GTP

ATP

NF-kB-P

Figure I The cGAS-STING signaling pathway. Exogenous and endogenous DNA activate cGAS to generate second messenger 2',3'-cGAMP. After 2',3'-cGAMP binds to the downstream receptor protein STING, STING transfers to golgi body and polymerization occurs, and then, TBKI, IRF3 and NF- $\kappa B$ were recruited. This promotes the phosphorylation of IRF3 and NF- $\mathrm{KB}$ and facilitates their entry into the nucleus, finally, the transcription of genes associated with inflammatory factors is activated. 
carcinogenic damage to tumor cells leads to the release of substantial amounts of DNA into the cytoplasm, continuously activating the STING signaling pathway in tumor cells and promoting chemokine production. These chemokines recruit numerous inflammatory cells, including immunosuppressive cells such as myeloid-derived suppressor cells (MDSCs) and M2 tumor-associated macrophages (TAMs), promoting tumor development. $^{33-37}$ Therefore, the use of STING agonists in such tumors may over-activate the STING signaling pathway and promote the development of tumors.

A study based on The Cancer Genome Atlas (TCGA) database assessed the correlation between STING expression and 28 tumor-infiltrating immune cells in 17 human malignant tumors. The results showed that the STING expression level in the tumor was positively correlated with the infiltration of most immune cell types. STING promotes the infiltration of antitumor immune effector cells (such as DCs and CD8 ${ }^{+}$T cells) and immunosuppressive cells (such as MDSCs and Treg cells) to the tumor site. ${ }^{38}$ A similar phenomenon exists in the microenvironment of mouse melanoma; the delivery of cGAMP nanoparticles to tumor sites promotes the activation of immune cells in the tumor microenvironment and significantly increases the proportion of MDSCs. ${ }^{39}$ Chronic Helicobacter pylori infection increases the risk of gastric cancer, which causes the upregulation of STING in vivo and the transduction of downstream IFN signals. However, this study also indicated that STING expression decreased in gastric cancer patients and was related to tumor size, development, and metastasis. ${ }^{40}$

Notably, in these studies, although STING agonists promoted the infiltration of immunosuppressive cells into tumors, antitumor immune cells infiltrating tumor tissues still dominated, implying that STING agonists still effectively inhibit tumor growth. Indoleamine 2.3-dioxygenase (IDO) is an enzyme of interest in immuno-oncology owing to its immunosuppressive effects resulting from its role in tryptophan catabolism. Tryptophan is an essential amino acid for the immune function of T cells. ${ }^{41,42}$ After tryptophan depletion inhibits $\mathrm{T}$ cell proliferation, its metabolite kynurenine directly inhibits $\mathrm{T}$ cell function and promotes tumor immune escape. ${ }^{4-45}$ In the mouse LLC model, STING signal activation promotes tumor growth by inducing IDO production in the tumor microenvironment. This effect is limited to weak antigenicity in the LLC tumor model, but the strong antigenicity displayed in the B16 melanoma model allows the activation of the STING signaling pathway to inhibit tumor growth. ${ }^{32}$ Thus, tumor antigenicity may be a crucial factor affecting the production of STING-mediated IDO in tumors.

\section{Inhibition of Tumors}

Activation of the cGAS-STING pathway promotes antitumor effects. The cGAS-STING pathway is responsible for the tumor response of antigen-presenting cells, leading to type I IFN secretion and T cell activation, inducing tumor recession. ${ }^{46}$ Mice deficient in STING are unable to mount an effective antitumor $\mathrm{T}$ cell immune response and inhibit the growth of melanocytic tumors, suggesting that STING signal transduction is necessary for $\mathrm{T}$ cell activation and effector function. ${ }^{47}$ In a colorectal adenocarcinoma model, STING activates DCs, promotes antigen presentation, and has an antitumor effect on $\mathrm{CD}^{+} \mathrm{T}$ cells; however, mice with STING deficiency is lack the antitumor effect of cGAMP. $^{48}$ In antigenic tumors, DNA damage caused by radiation activates the initial immune response regulated by STING signals. ${ }^{49}$ However, STING knockout affects the therapeutic effect of irradiation on tumors, whereas cGAMP addition improves the effect of irradiation treatment. $^{50}$ The STING agonist, 5.6-dimethylxanthenone-4-acetic acid (DMXAA), specifically binds to mouse STING instead of human STING. ${ }^{51}$ The results of in vivo experiments showed that DMXAA significantly reduces tumor volume, inhibits re-invasion by the same tumor cells, and inhibits tumor growth at untreated sites; however, these effects were dependent on the presence of STING. ${ }^{52}$ Additionally, the antitumor effects of STING were also observed in the azomethane/dextran sodium sulfate (AOM/DSS)-induced Escherichia coli tumor mouse model. ${ }^{29}$ AOM causes DNA damage and induces the expression of inflammatory cytokine-related genes via the STING signaling pathway. After STING knockout mice were treated with AOM/DSS, the colon displayed clear inflammatory cell infiltrates and the development of adenocarcinoma. These findings indicate that, in STINGdeficient mice (SKO), once the innate immune sensing deficiency of tumor DNA will destroy the generation of tumor-invasive $\mathrm{CD}^{+} \mathrm{T}$ cells. $^{29}$ STING constitutes a critical component of the host early response to intestinal damage and is essential for invigorating tissue repair pathways that may help prevent tumorigenesis. ${ }^{53}$ Thus, host cGAS-STING pathway activation in DCs and type I IFN induction promotes tumor antigen cross-expression, further activating $\mathrm{T}$ cells and playing an antitumor role. Cytoplasmic DNA activates the cGAS-STING signaling pathway, which plays a key role in cell senescence and is 
a crucial mechanism of tumor inhibition. Various stress conditions lead to cell senescence, arresting the cell cycle. $^{54,55}$ cGAS-STING pathway activation promotes the production of type I IFN and senescence-associated secretory phenotype factors, promoting senescence. ${ }^{56-58}$ Notably, the cGAS-STING pathway also promotes senescence induced by oncogenic Ras proteins. ${ }^{59}$ These studies suggest that activation of the cGAS-STING pathway inhibits cancer development by inducing cell senescence. Injecting cGAMP into the tumor also activates the STING signaling pathway of macrophages and induces $\mathrm{CD}_{11 \mathrm{~b}}{ }^{\text {mid }} \mathrm{Ly} 6 \mathrm{C}^{+} \mathrm{F} 4 / 80^{+} \mathrm{MHC} \mathrm{II}^{+}$mature macrophage migration to the tumor site. ${ }^{60}$ However, these macrophages tend to be of the M1-subtype, predominantly producing TNF- $\alpha$, rather than the negative regulator IL-10, and show strong phagocytic activity. ${ }^{60,61}$ Compared with immature MDSCs, STING signaling pathway-activated macrophages express higher levels of $\mathrm{C}-\mathrm{X}-\mathrm{C}$ motif ligand 10 (CXCL10), C-X-C motif ligand 11 (CXCL11), nitric oxide synthase (NOS2), and type I IFN genes. ${ }^{60,62,63}$

In addition to $\mathrm{T}$ cells and DCs, NK cells also play a vital role in the STING-mediated antitumor immune response. The antitumor effects of STING on NKsensitive tumors such as RMA-S lymphoma and B16BL6 melanoma are dependent on NK cells rather than T or B cells. ${ }^{64}$ A recent study also confirmed this conclusion through NK cell clearance experiments, which showed that NK cells play an influential role in the initial stage of the antitumor immune response mediated by the STING signaling pathway. ${ }^{9}$ Additionally, DNA damage in tumor cells induces cGAS-STING signaling pathway activation, thus upregulating the expression of natural killer cell group 2D (NKG2D) ligand. After STING and IRF3 were knocked-out in mouse tumor cells, the expression of an NKG2D ligand, retinoic acid early transcript (RAET1), was significantly reduced. ${ }^{65}$ Upregulated NKG2D ligands on the surface of tumor cells bind to NKG2D receptors on the surface of NK cells; thus, NK cell-mediated tumor cell killing is enhanced. ${ }^{66-68}$ Thus, NK cells play an influential role in the STING-mediated antitumor immune response, providing novel insights into the mechanism of antitumor immune responses mediated by STING pathway activation.

The activation of the STING signaling pathway in tumor cells promotes their apoptosis. After STING stimulation by cyclic diguanylate (c-di-GMP) in 4T1 breast cancer cells or overexpression in $\mathrm{McF}-7$ or T47D breast cancer cells, caspase-3 activity is enhanced, which is related to tumor cell apoptosis and leads to an increase in the apoptosis rate. ${ }^{69}$ This mechanism involves apoptosis due to IFN induction by STING signaling pathway activation and mitochondrial apoptosis pathway triggering and caspase-9 and caspase-3 induction via the promotion of IRF3 and Bcl-2-associated X protein (Bax) interactions in the mitochondria by STING in an IFN-independent mechanism. $^{70}$

STING agonists did not promote apoptosis in all types of tumor cells. Recent studies showed that STING agonists have no pro-apoptotic effect on B16F10 melanoma, CT26 colon cancer, HEPA 1-6 hepatoma, LL/2 Lewis lung cancer, human HSC-3, SCC-4 tongue squamous cell carcinoma, or other tumor cell lines. ${ }^{60,71-74}$ Since STING agonists are often used as antitumor therapeutic adjuvants, it is necessary to study the precise molecular mechanism underlying STING signal transduction and apoptosis. In addition to apoptosis, STING agonists promote pyroptosis, necrosis, and autophagy in tumor cells. ${ }^{75-80}$ Reportedly, stimulation of p53 primes cells for the production of interferons (through STING upregulation) and may activate negative-feedback within this signaling system by enhancing the production of suppressor of cytokine signaling 1 (SOCS1).

In addition to tumor cells and immune cells, another prominent member of the tumor microenvironment, stromal cells (such as endothelial cells and fibroblasts), also express STING genes. ${ }^{81-88}$ Tumor-derived DNA can be transferred from cell to cell by phagocytosis of apoptotic bodies. Additionally, when apoptotic tumor cells are cocultured with fibroblasts and endothelial cells, the fibroblasts and endothelial cells ingest tumor DNA, activating the cGAS-STING signaling pathway in the cytoplasm, inducing type I IFN production. ${ }^{88}$

Activation of the STING signaling pathway in stromal cells induces vascular remodeling. DMXAA, owing to its rapid and powerful antitumor angiogenesis activity, is used as an anti-vascular drug. This effectively controls tumor growth by regulating the vascular system in the tumor microenvironment but does not affect angiogenesis in normal tissues. ${ }^{89-91}$ A recent study found that, in addition to DMXAA, injection of other STING agonists, cGAMP, or ML RR-S2-CDA (mixed-linkage Rp, Rp dithio diastereomer c-di-AMP) in tumors could normalize the vascular system of primary or transplantable tumors. In STING gene knockout mice, this phenomenon disappeared, indicating that STING activation is essential for tumor vascular system normalization. This study showed that 
intratumoral STING activation normalizes the tumor vasculature and the tumor microenvironment, providing a rationale for combining STING-based immunotherapy and anti-angiogenic therapy. ${ }^{92}$ After STING activation in tumors, interferon- $\beta$ (IFN- $\beta$ ) production plays an critical role in angiogenesis. IFN- $\beta$, an anti-angiogenic cytokine, inhibits endothelial cell proliferation and capillary network formation, up-regulates vascular normalized gene expression, normalizes the tumor vascular system, promotes $\mathrm{CD}^{+} \mathrm{T}$ cell infiltration, and ultimately enhances antitumor immunity. ${ }^{92}$ Upon using the interferon receptor inhibitor to block type I IFN signaling, the STING-induced vascular changes are largely eliminated, suggesting that STING induces type I IFN production in the tumor vasculature and plays a key role in the treatment of tumors. ${ }^{85,92}$

\section{cGAS-STING in Tumor Metastasis}

In addition to its roles in oncogenesis and development, cGAS-STING is implicated in tumor metastasis. Activation of STING in tumor cells induces cell death through NF- $\kappa B$ signaling in the breast cancer environment, effectively limiting tumor migration and metastasis. STING is expressed at low levels in the MCF-7 breast cancer cell line; cell migration was inhibited in MCF-7 cells with upregulated STING expression. ${ }^{69,93}$ These results suggest that STING inhibits the migration and metastasis of breast cancer cells; however, the mechanism of action is unclear and may be related to NF- $\mathrm{KB}$ activity. ${ }^{69,94,95}$ Similarly, after STING was silenced, the migration and invasion of gastric cancer cells increased and the activities of both cytoplasmic DNA sensing and cGAMP in gastric cancer were inhibited. ${ }^{40}$ Wild-type mice and mice with a STING gene deletion were inoculated with melanoma cells, and the results showed that mice with STING gene deletion are more likely to develop lung metastasis than wild-type mice. This study showed that DCs uptake and sense the nuclear DNA released by dying cells to induce type I IFN. Remarkably, this molecular pathway requires STING, but not toll-like receptors (TLR) or NOD-like receptors (NLR) function, and results in the activation of IRF3 in a TBK1-dependent manner. ${ }^{96}$

IDO is activated by STING and promotes tumor growth. IDO catalyzes the transformation of L-tryptophan into $\mathrm{N}$-formyl kynurenine, promotes the immune escape of tumor cells, and limits the proliferation of $\mathrm{T}$ cells. $^{32,97}$ Notably, IDO expression increased in lymph nodes with tumor metastasis, and mice with defects in STING and IDO were more resistant to distant metastasis of LLC. ${ }^{32}$ Activation of the cGAS-STING signal stimulates programmed death ligand 1 (PD-L1) expression in tumor cells, thus mediating the immune escape of tumor cells. ${ }^{93}$ Human and mouse breast and lung cancer cells express protocadherin 7 ( $\mathrm{PCDH} 7)$, which promotes the assembly of carcinoma-astrocyte gap junctions composed of connexin 43 (Cx43). Once engaged with the astrocyte gap-junctional network, brain metastatic cancer cells use these channels to transfer the second messenger cGAMP to astrocytes, activating the STING pathway and the production of inflammatory cytokines such as interferon- $\alpha$ (IFN- $\alpha$ ) and TNF- $\alpha$. As paracrine signals, these factors activate the signal transducer and activator of transcription (STAT1) and NF- $\kappa$ B pathways in brain metastatic cells, thereby supporting tumor growth and chemoresistance. ${ }^{94}$ Another study showed that chromosomal instability promotes metastasis by sustaining a tumor cell-autonomous response to cytosolic DNA. Errors in chromosome segregation create a preponderance of micronuclei, whose rupture spills genomic DNA into the cytosol. This leads to the activation of the cGAS-STING cytosolic DNA-sensing pathway and downstream noncanonical NF- $\kappa B$ signaling. By subverting lethal epithelial responses to cytosolic DNA, chromosomally unstable tumor cells co-opt for chronic activation of innate immune pathways to spread to distant organs. ${ }^{98}$

\section{Agonists and Inhibitors of cGAS and STING}

The cGAS-STING signaling pathway is a double-edged sword in innate and adaptive immunity. Appropriate activators or inhibitors can regulate this pathway to promote immune function in the body. Therefore, we summarized the agonists and inhibitors of cGAS-STING in Table 1.

\section{Inhibitors of cGAS}

Agonists directly targeting cGAS have not been reported. Although some metal ions (such as manganese ions and zinc ions) can increase the enzymatic activity of cGAS, the required effective concentration is too high and is toxic in vivo, which is not conducive to subsequent drug development. ${ }^{18,99-102}$ However, there have been many studies on cGAS inhibitors. Based on high-performance liquid chromatography, suramin was confirmed to be an effective inhibitor. The results showed that suramin competes with DNA for binding to cGAS, thus inhibiting cGAS activity. Additionally, THP-1 cells treated with 
Table I Clinical Trials of STING Agonists

\begin{tabular}{|c|c|c|c|c|c|c|}
\hline Treatment & Agent & Target & Cancer Type & $\begin{array}{l}\text { Method of } \\
\text { Administration }\end{array}$ & Phase & $\begin{array}{l}\text { Clinicaltrial } \\
\text { ID }\end{array}$ \\
\hline \multirow{14}{*}{$\begin{array}{l}\text { Exclusive } \\
\text { application }\end{array}$} & ADU-SI00 & STING & Head and neck cancer & Intratumorally & Phase 2 & NCT03937|4| \\
\hline & E7766 & STING & Bladder neoplasms & Intravenously & Phase I & NCT04109092 \\
\hline & E7766 & STING & Lymphoma/advanced solid tumors & Intratumorally & Phase I & NCT04I44I4C \\
\hline & GSK37454I7 & STING & Neoplasms & Intravenously & Phase I & NCT03843359 \\
\hline & MK-1454 & STING & Lymphoma/solid tumors & Intratumorally & Phase I & NCT03010176 \\
\hline & BMS-98630I & STING & Solid tumors & Intratumorally & Phase I & NCT03956680 \\
\hline & SB 11285 & STING & Solid tumors & $\begin{array}{l}\text { Intratumorally/ } \\
\text { intravenously }\end{array}$ & Phase I & NCT04096638 \\
\hline & MK-2II8 & STING & Lymphoma/solid tumors & $\begin{array}{l}\text { Intratumorally/ } \\
\text { subcutaneously }\end{array}$ & Phase I & NCT03249792 \\
\hline & DMXAA & STING & Advanced solid tumors & Intravenously & Phase I & NCT0I29970I \\
\hline & DMXAA & STING & Advanced solid tumors & Intravenously & Phase I & NCT0I278849 \\
\hline & DMXAA & STING & Advanced solid tumors & Not specified & Phase I & NCT0I278758 \\
\hline & DMXAA & STING & Solid tumors & Intravenously & Phase I & NCT00856336 \\
\hline & DMXAA & STING & Solid tumors & Intravenously & Phase I & NCT00003697 \\
\hline & DMXAA & STING & Solid tumors & Intravenously & Phase I & NCT00863733 \\
\hline \multirow{12}{*}{$\begin{array}{l}\text { Combined with } \\
\text { chemotherapy }\end{array}$} & DMXAA+docetaxel & STING & Advanced solid tumors & Not specified & Phase I & NCT0I 285453 \\
\hline & $\mathrm{DMXAA+docetaxel}$ & STING & Advanced urothelial carcinoma & Intravenously & Phase 2 & NCT01071928 \\
\hline & $\mathrm{DMXAA+docetaxel}$ & STING & Non-small cell lung carcinoma & Intravenously & Phase 3 & NCT00738387 \\
\hline & DMXAA+docetaxel & STING & Prostate cancer & Intravenously & Phase 2 & NCT00III6I8 \\
\hline & $\begin{array}{l}\text { DMXAA+docetaxel or } \\
\text { paclitaxel or carboplatin }\end{array}$ & STING & Advanced solid tumors & Intravenously & Phase I & NCT0 1240642 \\
\hline & $\begin{array}{l}\text { DMXAA+taxane-based } \\
\text { chemotherapy }\end{array}$ & STING & Advanced solid tumors & Not specified & Phase I & NCT0I29038C \\
\hline & $\begin{array}{l}\text { DMXAA+carboplatin/ } \\
\text { paclitaxel }\end{array}$ & STING & Non-small cell lung carcinoma & Intravenously & Phase I & NCT00674102 \\
\hline & $\begin{array}{l}\text { DMXAA+carboplatin/ } \\
\text { paclitaxel }\end{array}$ & STING & Non-small cell lung carcinoma & Not specified & Phase $1 / 2$ & NCT00832494 \\
\hline & $\begin{array}{l}\text { DMXAA+carboplatin/ } \\
\text { paclitaxel }\end{array}$ & STING & Non-small cell lung carcinoma & Intravenously & Phase 3 & NCT00662597 \\
\hline & $\begin{array}{l}\text { DMXAA+carboplatin, } \\
\text { cetuximab and paclitaxel }\end{array}$ & STING & Solid tumors & Intravenously & Phase I & NCT01031212 \\
\hline & $\begin{array}{l}\text { DMXAA+carboplatin/ } \\
\text { paclitaxel }\end{array}$ & STING & Small cell lung carcinoma & Intravenously & Phase 2 & NCT0I057342 \\
\hline & $\begin{array}{l}\text { DMXAA+fluvoxamine (core } \\
\text { phase), DMXAA+paclitaxel/ } \\
\text { docetaxel or carboplatin } \\
\text { (extension phase) }\end{array}$ & STING & Solid tumors & Not specified & Phase I & NCT0I2994IS \\
\hline
\end{tabular}

(Continued) 
Table I (Continued).

\begin{tabular}{|l|l|l|l|l|l|l|}
\hline Treatment & Agent & Target & Cancer Type & $\begin{array}{l}\text { Method of } \\
\text { Administration }\end{array}$ & $\begin{array}{l}\text { Phase } \\
\text { ID }\end{array}$ & \\
\hline $\begin{array}{l}\text { Combined with } \\
\text { immunotherapy }\end{array}$ & MK-1454+pembrolizumab & STING+PD-I & Head and neck cancer & Intratumorally & Phase 2 & NCT04220866 \\
\cline { 2 - 7 } & ADU-SI00+PDR00I & STING+PD-I & Lymphoma/solid tumors & $\begin{array}{l}\text { Intratumorally } \\
+ \text { intravenously }\end{array}$ & Phase I & NCT03I72936 \\
\cline { 2 - 7 } & ADU-SI00+/- Ipilimumab & $\begin{array}{l}\text { STING+/-CTLA- } \\
4\end{array}$ & Lymphoma/solid tumors & Intratumorally & Phase I & NCT02675439 \\
\hline
\end{tabular}

suramin had reduced IFN- $\beta$ expression. ${ }^{103}$ Quinacrine and chloroquine are antimalarial drugs that decrease cGAS activity and have been used to treat severe debilitating diseases associated with type I IFNs. Through in silico screening of the drug library, computational analysis confirmed that quinacrine and chloroquine are effective inhibitors of IFN- $\beta$ and act by inhibiting dsDNA stimulation of cGAS. ${ }^{104-106}$ Other studies found that epigallocatechin gallate (EGCG) in tea polyphenols indirectly inhibits the binding of cGAS to DNA by inhibiting the activity of GTPase-activating protein-binding protein 1 (G3BP1). ${ }^{107-109}$

These compounds, screened against the structure of the cGAS enzyme active region or the structure of the cGAS/ DNA complex, have weak biological activity. Establishing a high-throughput and high-sensitivity detection platform can obtain more comprehensive protein structure data and promote small molecule research targeting cGAS. Increasing evidence suggests that protein-mediated signal transduction can be effectively regulated by regulating protein post-translational modifications. Hence, the development of compounds targeting protein post-translational modifications is a future research direction.

\section{Agonists of STING}

Activation of the STING signaling pathway promotes the expression of type I IFN, which plays a key role in antitumor immunity. Therefore, the development of agonists that target STING is a popular research agenda in this field. Studies on STING agonists focus on the optimization of cyclic dinucleotide (CDN) analogs and the screening of novel small molecule agonists. ${ }^{110-113} \mathrm{CDNs}$, effective STING activators, are second messengers common in the immune systems of prokaryotes and eukaryotes. ${ }^{114-116}$ There are two sources of CDNs: the cGAS pathway, which produces the atypical dinucleotide $2^{\prime}, 3^{\prime}$-cGAMP after the detection of cytoplasmic DNA; the other is found in the cytoplasm owing to the presence of pathogens. ${ }^{112,117-119}$ Numerous studies found that CDNs have strong antitumor effects and application prospects in the treatment of melanoma, colon cancer, and oral cancer. ${ }^{39,120-122}$ However, there are limitations in the use of CDNs as candidate drugs. The molecular weights of CDNs are large, the net charge and polarity distribution strongly limit its membrane channeling and cell absorption, and the phosphodiester bond is easily enzymolyzed. ${ }^{123,124}$ The core strategy for developing the candidate drug, ADUS100, is to modify the phosphodiester group. This drug is currently in phase I clinical trials, primarily for use in patients with advanced/metastatic solid tumors or lymphomas. ${ }^{125}$

DMXAA is a non-nucleoside agonist and that is only effective to murine STING but not human STING, DMXAA induces type I IFN and has strong antitumor effects. After DMXAA activates the STING signaling pathway, it stimulates the $\mathrm{CD}^{+} \mathrm{T}$ cell response in the acute myeloid leukemia (AML) model, and improves survival time in vivo through adaptive immunity. These data demonstrate that STING is a promising immunotherapeutic target in AML. ${ }^{126}$ In the wild-type mouse model of B16 melanoma, $500 \mu \mathrm{g}$ of DMXAA injected into the tumor induced tumor regression and rejection in most mice, whereas STING knockout mice did not show a therapeutic effect. ${ }^{127}$ In tumors of mice treated with DMXAA and hypoxia-inducible factor-1 alpha (HIF-1 $\alpha$ ) inhibitors, the numbers of $\mathrm{M} 1$ macrophages, $\mathrm{CD}^{+}$cytotoxic lymphocytes, NK cells, and, to a lesser extent, $\mathrm{CD} 4^{+}$ lymphocytes were increased. Combination therapy appears to be an effective therapeutic option. ${ }^{128}$ DMXAA causes tumor site-specific vascular disruption in murine non-small cell lung cancer, and similar to the endogenous noncanonical cyclic dinucleotide STING agonist, 2', $3^{\prime}$ - 
cGAMP, induces M2 macrophage repolarization. These findings demonstrate that the selection of preclinical model and the anatomical site of a tumor determines the vascular disrupting effectiveness of DMXAA, and support the idea that STING agonists have therapeutic utility as TAM repolarizing agents. ${ }^{36}$

\section{Inhibitors of STING}

Recent studies found that the abnormal activation of STING leads to immune dysfunction and induces autoimmune diseases such as Aicardi-Goutieres syndrome, systemic lupus erythematosus, and STING-associated vasculopathy with onset in infancy (SAVI), drawing attention to the need for the development of STING inhibitors. $^{129-131}$ Two nitrofuran derivatives, C-178 and C-176, covalently act on the predicted transmembrane cysteine residue Cys91, thus blocking activated STING by palmitoylation. The species-specificity of $\mathrm{C}-178$ and $\mathrm{C}-176$ indicated that the compounds were targeted to mouse STING (mmSTING) and not to human STING (hsSTING). H-151 has an inhibitory effect on hsSTING, inhibits type I IFN signaling, reduces TBK1 phosphorylation, and suppresses hsSTING palmitoylation. ${ }^{132}$

\section{Application of cGAS-STING in Tumor Immunotherapy Exclusive Application of cGAS-STING Agonists}

Currently, STING agonists have shown ideal therapeutic effects in preclinical studies and clinical trials of a variety of tumors. ${ }^{133-138}$ The STING agonist DMXAA proved, in animal models, that it can effectively inhibit the growth of various solid tumors; conversely, in a phase $ш$ clinical trial of human non-small cell lung cancer, DMXAA did not activate STING signaling pathways in the human body, declaring the clinical trial a failure. ${ }^{139,140}$ As a CDN that activates both mice and human STING, it inhibits the growth of melanoma, breast cancer, colon cancer, pancreatic cancer, skin cancer, B-cell lymphoma, and other types of tumors as well as the growth of distant tumors. ${ }^{39,52,70,87,141-143}$ Among these, ADU-S100 (also known as ML RR-S2 CDA or MIW815) alters the microenvironment of solid tumors, activates $\mathrm{CD} 8^{+} \mathrm{T}$ cells, and produces long-lasting antitumor effects. As a synthetic cyclic dinucleotide, ADU-S100 is the first STING pathway activator in clinical trials. In 2015, Novartis partnered with Aduro on the ADU-S100. This clinical trial involved more than 20 cancer types, all showing initial antitumor results. Clinical results showed that after ADU-S100 treatment, 2 of the 40 patients had significantly reduced tumor sizes, 11 maintained stable disease, and 1 maintained stable disease for more than 1 year. The total objective response rate was $5 \%$, and the disease control rate was $32.5 \% .{ }^{144}$ However, in December 2019, Novartis terminated the development of ADU-S100 due to poor Phase I data in combination with Spartalizumab, an antibody against PD-1.

\section{cGAS-STING Agonists Combined with Chemotherapy and Radiotherapy}

Chemotherapy and radiotherapy are the primary treatment methods for solid tumors. ${ }^{145}$ Studies show that the toxic effects of radiation and traditional chemical drugs induce the formation of micronucleus and cytoplasmic chromatin fragments and activate the cGAS-STING signaling pathway. ${ }^{146,147}$ For example, the chemotherapeutic drugs cisplatin and etoposide induce the activation of the cGASSTING signaling pathway through DNA damage and solute leakage. ${ }^{30}$ Although chemotherapy and radiation do not target the cGAS-STING signaling pathway, these therapies activate the cGAS-STING signaling pathway and enhance the antitumor immune response. STING agonists combined with radiotherapy or chemotherapy synergistically enhance the antitumor effect and reduce the toxicity and side effects caused by radiotherapy and chemotherapy. Inflammatory pathways activated by STING ligands generate powerful adjuvant activity to enhance adaptive immune responses against tumor antigens released by radiotherapy. In a murine pancreatic cancer model, combining CT-guided radiotherapy with a novel ligand of murine and human STING synergized to control local and distant tumors. Mechanistic investigations revealed early $\mathrm{T}$ cell-independent and TNF- $\alpha$-dependent hemorrhagic necrosis, followed later by $\mathrm{CD}^{+} \mathrm{T}$ cell-dependent control of residual disease. ${ }^{148}$ cGAMP improved the antitumor activity of 5-FU and reduced its toxicity. These results demonstrated that cGAMP is a novel antitumor agent and has potential applications in cancer immunotherapy. ${ }^{48}$

\section{cGAS-STING Agonists Combined with Tumor Vaccines}

Owing to central and peripheral tolerance, tumor-associated antigen is weakly immunogenic; therefore, appropriate adjuvants are essential for overcoming tolerability and enhancing 
tumor-specific immune responses. ${ }^{149-151}$ STING agonists can be delivered with tumor antigen peptide as a vaccine adjuvant to overcome tolerance, enhancing antitumor immune responses. ${ }^{35}$ Mice with metastatic breast cancer (the 4T1 model) were therapeutically immunized with an attenuated Listeria monocytogenes (LM)-based vaccine, expressing the tumor-associated antigen Mage-b (LM-Mb), followed by multiple low doses of c-di-GMP. This treatment resulted in the near-elimination of metastases. ${ }^{35}$ STINGVAX, formed by the combination of STING agonist and tumor vaccine that secretes GM-CSF, has antitumor effects on melanoma, colon cancer, digestive tract squamous cell carcinoma, pancreatic cancer, and many other cancer models. Compared with the GM-CSF-tumor vaccine (GM-VAX) without the STING agonist, STING-VAX-treated mice showed a significantly higher number of infiltrated $\mathrm{CD} 8^{+}$ IFN $\gamma^{+}$T cells. ${ }^{141}$ The STING-VAX injection in the contralateral part of the B16 transplanted melanoma significantly inhibited tumor size in a dose-dependent manner. The combined STING-VAX enhanced $\mathrm{T}$ cell infiltration in tumor tissues compared with the vaccine of single GMCSF-secreting cancer cells. Furthermore, several tumorbearing mouse models demonstrated the strong antitumor effects of STING-VAX. The feasibility of STING-based cancer vaccines was verified in mice bearing pancreatic cancer and melanoma. ${ }^{152,153}$

\section{cGAS-STING Agonists Combined with Immune Checkpoint Blockade Therapy}

Cytotoxic T lymphocyte antigen-4 (CTLA-4) and programmed cell death protein 1 (PD-1) are co-inhibitory molecules that regulate $\mathrm{T}$ lymphocyte activation; they can cause T cell dysfunction, allowing tumor cells to evade host immune responses. ${ }^{154-156}$ Therefore, antagonists targeting CTLA-4 and PD-1/PD-L1 weaken these tumor-induced inhibitory signals and enhance host antitumor immunity. ${ }^{157-159}$ Due to the small number of infiltrating $\mathrm{CD} 8^{+} \mathrm{T}$ cells in the tumor microenvironment, the therapeutic efficacy of immune checkpoint inhibitors remains to be improved. ${ }^{160-162}$ However, injection of STING agonists into the tumor induces chemokine production, including C-C motif ligand 5 (CCL5) and C-X-C motif ligand 10 (CXCL10), which promote $\mathrm{T}$ cell infiltration of the tumor; therefore, STING agonists are ideal sensitizers for anti-PD-1/ PD-L1 therapy. ${ }^{163}$ STING agonists upregulate PD-L1 expression in tumor cells and enhance the therapeutic effect of the anti-PD-1/PD-L1 antibody, whereas the anti-PD-1/PD-L1 antibody neutralizes the immunosuppressive effect of STING agonists. ${ }^{141}$

A STING agonist, combined with anti-PD-1 and antiCTLA-4 antibodies, significantly enhances antitumor effects against melanoma treatment. ${ }^{81}$ In the squamous cell carcinoma model, a STING agonist combined with an anti--PD-1 antibody had stronger antitumor effects than single drug therapy. ${ }^{142,164}$ Additionally, through the method of sustained and controlled release, the nano-preparation promotes the accumulation of STING agonists in the tumor site, which enhances the immune activation effect of the STING agonist and reduces its toxic effects. ${ }^{39}$ Thus, the combination of STING agonists, delivered by nanoparticles, and anti-PD-1 antibodies slows tumor growth significantly. ${ }^{165}$ Recently, the phase I clinical trial of the STING agonist MK-1454 and PD-1 immune checkpoint blockade was concluded; the results confirmed that intratumoral MK-1454 injection leads to tumor regression and enhances the effect of antiPD-1 therapy. ${ }^{144}$ Another study found that an intact cGASSTING pathway was indispensable to maximize antiCTLA-4 treatment effects. Mice bearing the B16 melanoma received an injection of irradiated tumor cells and subsequent anti-CTLA-4 treatment. After combined treatment with anti-CTLA-4 and a STING agonist, no significant abscopal tumor elimination effect was detected in mice inoculated with STING-deficient B16 tumor cells. Meanwhile, STING deficiency markedly impaired $\mathrm{CD} 8^{+}$ $\mathrm{T}$ infiltration of the tumor bed. ${ }^{147}$

\section{cGAS-STING Agonists Combined with CAR-T Cell Therapy}

Cancer immunotherapy using chimeric antigen receptormodified T (CAR-T) cells has excellent clinical efficacy for hematological malignancies. ${ }^{166,167}$ Despite the progress in treating hematological malignancies, challenges remain in the use of CAR-T cell therapy for solid tumors. ${ }^{168}$ In this landscape, most studies focus on improving CAR-T cells and overcoming the unfavorable effects of the tumor microenvironment in solid tumors. ${ }^{169,170}$ A recent study demonstrated that codelivery of STING agonists with CAR-T cell therapy stimulates immune responses to eliminate tumor cells that are not recognized by the adoptively transferred lymphocytes. Thus, these devices may improve the effectiveness of CAR-T cell therapy in immunocompetent orthotopic mouse models of pancreatic cancer and melanoma, and STING agonists may facilitate protection against the emergence of escape variants. ${ }^{171}$ 


\section{Concluding Remarks}

The cGAS-STING signaling pathway is related to the occurrence, development, and metastasis of tumors, and the body can enhance natural antitumor immunity by activating the cGAS-STING signaling pathway. An in-depth study of the cGAS-STING signaling pathway will deepen the understanding of the innate immune antitumor mechanism and provide a theoretical basis for the design of resistance-free tumor therapies.

\section{Acknowledgments}

This study was supported by The National Natural Science Foundation of China $(81904231,82072978,82072979)$, the China Postdoctoral Science Foundation (2020M672369), and the Natural Science Foundation of Hubei Province (2020CFB861).

\section{Disclosure}

The authors declare that they have no competing interests.

\section{References}

1. Lei X, Lei Y, Li JK, et al. Immune cells within the tumor microenvironment: biological functions and roles in cancer immunotherapy. Cancer Lett. 2020;470:126-133. doi:10.1016/j. canlet.2019.11.009

2. Marzagalli M, Ebelt ND, Manuel ER. Unraveling the crosstalk between melanoma and immune cells in the tumor microenvironment. Semin Cancer Biol. 2019;59:236-250. doi:10.1016/j.semcancer.2019.08.002

3. Galon J, Bruni D. Tumor Immunology and Tumor Evolution: intertwined Histories. Immunity. 2020;52(1):55-81. doi:10.1016/ j.immuni.2019.12.018

4. Bose D. cGAS/STING Pathway in Cancer: jekyll and Hyde Story of Cancer Immune Response. Int $J$ Mol Sci. 2017;18:11. doi:10.3390/ijms18112456

5. Hopfner KP, Hornung V. Molecular mechanisms and cellular functions of cGAS-STING signalling. Nat Rev Mol Cell Biol. 2020;21(9):501-521. doi:10.1038/s41580-020-0244-x

6. Saeed A, Ruan X, Guan H, et al. Regulation of cGAS-Mediated Immune Responses and Immunotherapy. Adv Sci. 2020;7 (6):1902599. doi:10.1002/advs.201902599

7. Zierhut C, Funabiki H. Regulation and Consequences of cGAS Activation by Self-DNA. Trends Cell Biol. 2020;30(8):594-605. doi:10.1016/j.tcb.2020.05.006

8. Deb P, Dai J, Singh S, et al. Triggering of the cGAS-STING Pathway in Human Plasmacytoid Dendritic Cells Inhibits TLR9-Mediated IFN Production. J Immunol. 2020;205 (1):223-236. doi:10.4049/jimmunol.1800933

9. Watkins-Schulz R, Tiet P, Gallovic MD, et al. A microparticle platform for STING-targeted immunotherapy enhances natural killer cell- and CD8(+) T cell-mediated anti-tumor immunity. Biomaterials. 2019;205:94-105. doi:10.1016/j.biomaterials.201 9.03.011

10. Mantovani A, Marchesi F, Malesci A, et al. Tumour-associated macrophages as treatment targets in oncology. Nat Rev Clin Oncol. 2017;14(7):399-416. doi:10.1038/nrclinonc.2016.217
11. Baumhoer D, Amary F, Flanagan AM. An update of molecular pathology of bone tumors. Lessons learned from investigating samples by next generation sequencing. Genes Chromosomes Cancer. 2019;58(2):88-99. doi:10.1002/gcc.22699

12. Fridman WH, Zitvogel L, Sautes-Fridman C, et al. The immune contexture in cancer prognosis and treatment. Nat Rev Clin Oncol. 2017;14(12):717-734. doi:10.1038/nrclinonc.2017.101

13. Grivennikov SI, Greten FR, Karin M. Immunity, inflammation, and cancer. Cell. 2010;140(6):883-899. doi:10.1016/j. cell.2010.01.025

14. Elinav E, Nowarski R, Thaiss CA, et al. Inflammation-induced cancer: crosstalk between tumours, immune cells and microorganisms. Nat Rev Cancer. 2013;13(11):759-771. doi:10.1038/nrc3611

15. Gajewski TF, Corrales L. New perspectives on type I IFNs in cancer. Cytokine Growth Factor Rev. 2015;26(2):175-178. doi:10.1016/j.cytogfr.2015.01.001

16. Rautela J, Baschuk N, Slaney CY, et al. Loss of host type-I IFN signaling accelerates metastasis and impairs NK-cell antitumor function in multiple models of breast cancer. Cancer Immunol Res. 2015;3 (11):1207-1217. doi:10.1158/2326-6066.CIR-15-0065

17. Sun L, Wu J, Du F, et al. Cyclic GMP-AMP synthase is a cytosolic DNA sensor that activates the type I interferon pathway. Science. 2013;339(6121):786-791. doi:10.1126/ science. 1232458

18. Wang C, Guan Y, Lv M, et al. Manganese Increases the Sensitivity of the cGAS-STING Pathway for Double-Stranded DNA and Is Required for the Host Defense against DNA Viruses. Immunity. 2018;48(4):675-87 e7. doi:10.1016/j. immuni.2018.03.017

19. Zhou W, Whiteley AT, de Oliveira Mann CC, et al. Structure of the Human cGAS-DNA Complex Reveals Enhanced Control of Immune Surveillance. Cell. 2018;174(2):300-11 e11. doi:10.1016/j.cell.2018.06.026

20. Ablasser A, Goldeck M, Cavlar T, et al. cGAS produces a 2'-5'linked cyclic dinucleotide second messenger that activates STING. Nature. 2013;498(7454):380-384. doi:10.1038/ nature 12306

21. Pepin G, Gantier MP. cGAS-STING Activation in the Tumor Microenvironment and Its Role in Cancer Immunity. Adv Exp Med Biol. 2017;1024:175-194. doi:10.1007/978-981-10-598728

22. Civril F, Deimling T, de Oliveira Mann CC, et al. Structural mechanism of cytosolic DNA sensing by cGAS. Nature. 2013;498(7454):332-337. doi:10.1038/nature12305

23. Zhang X, Wu J, Du F, et al. The cytosolic DNA sensor cGAS forms an oligomeric complex with DNA and undergoes switch-like conformational changes in the activation loop. Cell Rep. 2014;6(3):421-430. doi:10.1016/j.celrep.2014.01.003

24. Andreeva L, Hiller B, Kostrewa D, et al. cGAS senses long and HMGB/TFAM-bound U-turn DNA by forming protein-DNA ladders. Nature. 2017;549(7672):394-398. doi:10.1038/ nature 23890

25. Shang G, Zhu D, Li N, et al. Crystal structures of STING protein reveal basis for recognition of cyclic di-GMP. Nat Struct Mol Biol. 2012;19(7):725-727. doi:10.1038/nsmb.2332

26. Zhao B, Du F, Xu P, et al. A conserved PLPLRT/SD motif of STING mediates the recruitment and activation of TBK1. Nature. 2019;569(7758):718-722. doi:10.1038/s41586-019-1228-x

27. Zhao B, Shu C, Gao X, et al. Structural basis for concerted recruitment and activation of IRF-3 by innate immune adaptor proteins. Proc Natl Acad Sci U S A. 2016;113(24):E3403. doi:10.1073/pnas.1603269113

28. Ablasser A, Chen ZJ. cGAS in action: expanding roles in immunity and inflammation. Science. 2019;363:6431. doi:10.1126/ science.aat 8657 
29. Ahn J, Konno H, Barber GN. Diverse roles of STING-dependent signaling on the development of cancer. Oncogene. 2015;34 (41):5302-5308. doi:10.1038/onc.2014.457

30. Ahn J, Xia T, Konno H, et al. Inflammation-driven carcinogenesis is mediated through STING. Nat Commun. 2014;5:5166. doi:10.1038/ncomms6166

31. Liu H, Zhang H, Wu X, et al. Nuclear cGAS suppresses DNA repair and promotes tumorigenesis. Nature. 2018;563 (7729):131-136. doi:10.1038/s41586-018-0629-6

32. Lemos H, Mohamed E, Huang L, et al. STING Promotes the Growth of Tumors Characterized by Low Antigenicity via IDO Activation. Cancer Res. 2016;76(8):2076-2081. doi:10.1158/ 0008-5472.CAN-15-1456

33. Zhang CX, Ye SB, Ni JJ, et al. STING signaling remodels the tumor microenvironment by antagonizing myeloid-derived suppressor cell expansion. Cell Death Differ. 2019;26 (11):2314-2328. doi:10.1038/s41418-019-0302-0

34. Mohamed E, Sierra RA, Trillo-Tinoco J, et al. The Unfolded Protein Response Mediator PERK Governs Myeloid Cell-Driven Immunosuppression in Tumors through Inhibition of STING Signaling. Immunity. 2020;52(4):668-82 e7. doi:10.1016/j. immuni.2020.03.004

35. Chandra D, Quispe-Tintaya W, Jahangir A, et al. STING ligand c-di-GMP improves cancer vaccination against metastatic breast cancer. Cancer Immunol Res. 2014;2(9):901-910. doi:10.1158/ 2326-6066.CIR-13-0123

36. Downey CM, Aghaei M, Schwendener RA, et al. DMXAA causes tumor site-specific vascular disruption in murine nonsmall cell lung cancer, and like the endogenous non-canonical cyclic dinucleotide STING agonist, 2'3'-cGAMP, induces M2 macrophage repolarization. PLoS One. 2014;9(6):e99988. doi: 10.1371 /journal.pone. 0099988

37. Ma R, Ji T, Chen D, et al. Tumor cell-derived microparticles polarize M2 tumor-associated macrophages for tumor progression. Oncoimmunology. 2016;5(4):e1118599. doi:10.1080/2162402X.2015.1118599

38. An X, Zhu Y, Zheng T, et al. An Analysis of the Expression and Association with Immune Cell Infiltration of the cGAS/STING Pathway in Pan-Cancer. Mol Ther Nucleic Acids. 2019;14:80-89. doi:10.1016/j.omtn.2018.11.003

39. Shae D, Becker KW, Christov P, et al. Endosomolytic polymersomes increase the activity of cyclic dinucleotide STING agonists to enhance cancer immunotherapy. Nat Nanotechnol. 2019;14 (3):269-278. doi:10.1038/s41565-018-0342-5

40. Song S, Peng P, Tang Z, et al. Decreased expression of STING predicts poor prognosis in patients with gastric cancer. Sci Rep. 2017;7:39858. doi:10.1038/srep39858

41. Selvan SR, Dowling JP, Kelly WK, et al. Indoleamine 2,3-dioxygenase (IDO): biology and Target in Cancer Immunotherapies. Curr Cancer Drug Targets. 2016;16 (9):755-764. doi:10.2174/1568009615666151030102250

42. Yentz S, Smith D. Indoleamine 2,3-Dioxygenase (IDO) Inhibition as a Strategy to Augment Cancer Immunotherapy. BioDrugs. 2018;32(4):311-317. doi:10.1007/s40259-018-0291-4

43. Prendergast GC, Malachowski WJ, Mondal A, et al. Indoleamine 2,3-Dioxygenase and Its Therapeutic Inhibition in Cancer. Int Rev Cell Mol Biol. 2018;336:175-203. doi:10.1016/bs. ircmb.2017.07.004

44. Davar D, Bahary N. Modulating Tumor Immunology by Inhibiting Indoleamine 2,3-Dioxygenase (IDO): recent Developments and First Clinical Experiences. Target Oncol. 2018;13(2):125-140. doi:10.1007/s11523-017-0547-9

45. Hornyak L, Dobos N, Koncz G, et al. The Role of Indoleamine-2,3-Dioxygenase in Cancer Development, Diagnostics, and Therapy. Front Immunol. 2018;9:151. doi:10.3389/fimmu.2018.00151
46. Woo SR, Fuertes MB, Corrales L, et al. STING-dependent cytosolic DNA sensing mediates innate immune recognition of immunogenic tumors. Immunity. 2014;41(5):830-842. doi:10.1016/j. immuni.2014.10.017

47. Sen T, Rodriguez BL, Chen L, et al. Targeting DNA Damage Response Promotes Antitumor Immunity through STING-Mediated T-cell Activation in Small Cell Lung Cancer. Cancer Discov. 2019;9(5):646-661. doi:10.1158/2159-8290.CD18-1020

48. Li T, Cheng H, Yuan H, et al. Antitumor Activity of cGAMP via Stimulation of cGAS-cGAMP-STING-IRF3 Mediated Innate Immune Response. Sci Rep. 2016;6:19049. doi:10.1038/ srep19049

49. Durante M, Formenti SC. Radiation-Induced Chromosomal Aberrations and Immunotherapy: micronuclei, Cytosolic DNA, and Interferon-Production Pathway. Front Oncol. 2018;8:192. doi:10.3389/fonc.2018.00192

50. Deng L, Liang H, Xu M, et al. STING-Dependent Cytosolic DNA sensing promotes radiation-induced type interferon-dependent antitumor immunity in immunogenic tumors. Immunity. 2014;41 (5):843-852. doi:10.1016/j.immuni.2014.10.019

51. Ceron S, North BJ, Taylor SA, et al. The STING agonist 5,6-dimethylxanthenone-4-acetic acid (DMXAA) stimulates an antiviral state and protects mice against herpes simplex virus-induced neurological disease. Virology. 2019;529:23-28. doi:10.1016/j.virol.2019.01.006

52. Corrales L, Glickman LH, McWhirter SM, et al. Direct Activation of STING in the tumor microenvironment leads to potent and systemic tumor regression and immunity. Cell Rep. 2015;11(7):1018-1030. doi:10.1016/j.celrep.2015.04.031

53. Ki HH, Lee JH, Lee HY, et al. Triticum aestivum Sprouts Extract Inhibits Azoymethane (AOM)/Dextran Sodium Sulfate (DSS)-Induced Colon Carcinogenesis in Mice. Nutr Cancer. 2018;70(6):928-937. doi:10.1080/01635581.2018.1490447

54. Campisi J, d'Adda Di Fagagna F. Cellular senescence: when bad things happen to good cells. Nat Rev Mol Cell Biol. 2007;8 (9):729-740. doi:10.1038/nrm2233

55. Childs BG, Durik M, Baker DJ, et al. Cellular senescence in aging and age-related disease: from mechanisms to therapy. Nat Med. 2015;21(12):1424-1435. doi:10.1038/nm.4000

56. Han X, Chen H, Gong H, et al. Autolysosomal degradation of cytosolic chromatin fragments antagonizes oxidative stress-induced senescence. J Biol Chem. 2020;295 (14):4451-4463. doi:10.1074/jbc.RA119.010734

57. Blasiak J. Senescence in the pathogenesis of age-related macular degeneration. Cell Mol Life Sci. 2020;77(5):789-805. doi:10.1007/s00018-019-03420-x

58. Loo TM, Miyata K, Tanaka Y, et al. Cellular senescence and senescence-associated secretory phenotype via the cGAS-STING signaling pathway in cancer. Cancer Sci. 2020;111(2):304-311. doi:10.1111/cas.14266

59. Hari P, Millar FR, Tarrats N, et al. The innate immune sensor Toll-like receptor 2 controls the senescence-associated secretory phenotype. Sci Adv. 2019;5(6):eaaw0254. doi:10.1126/sciadv. aaw0254

60. Ohkuri T, Kosaka A, Ishibashi K, et al. Intratumoral administration of cGAMP transiently accumulates potent macrophages for anti-tumor immunity at a mouse tumor site. Cancer Immunol Immunother. 2017;66(6):705-716. doi:10.1007/s00262-0171975-1

61. Ohkuri T, Kosaka A, Nagato T, et al. Effects of STING stimulation on macrophages: STING agonists polarize into "classically" or "alternatively" activated macrophages? Hum Vaccin Immunother. 2018;14(2):285-287. doi:10.1080/21645515.20 17.1395995 
62. Domvri K, Petanidis S, Zarogoulidis P, et al. Treg-dependent immunosuppression triggers effector $\mathrm{T}$ cell dysfunction via the STING/ILC2 axis. Clin Immunol. 2020:108620. doi:10.1016/j. clim.2020.108620

63. Benmerzoug S, Rose S, Bounab B, et al. STING-dependent sensing of self-DNA drives silica-induced lung inflammation. Nat Commun. 2018;9(1):5226. doi:10.1038/s41467-018-07425-1

64. Marcus A, Mao AJ, Lensink-Vasan M, et al. Tumor-Derived cGAMP Triggers a STING-Mediated Interferon Response in Non-tumor Cells to Activate the NK Cell Response. Immunity. 2018;49(4):754-63 e4. doi:10.1016/j.immuni.2018.09.016

65. Lam AR, Bert NL, Ho SS, et al. RAE1 ligands for the NKG2D receptor are regulated by STING-dependent DNA sensor pathways in lymphoma. Cancer Res. 2014;74(8):2193-2203. doi:10.1158/0008-5472.CAN-13-1703

66. Molfetta R, Quatrini L, Santoni A, et al. Regulation of NKG2D-Dependent NK Cell Functions: the Yin and the Yang of Receptor Endocytosis. Int J Mol Sci. 2017;18:8. doi:10.3390/ ijms 18081677

67. Parihar R, Rivas C, Huynh M, et al. NK Cells Expressing a Chimeric Activating Receptor Eliminate MDSCs and Rescue Impaired CAR-T Cell Activity against Solid Tumors. Cancer Immunol Res. 2019;7(3):363-375. doi:10.1158/2326-6066.CIR-18-0572

68. Chen T, Zhang T, Liu C, et al. NK cells suppress CD8(+) T cell immunity via NKG2D in severe aplastic anemia. Cell Immunol. 2019;335:6-14. doi:10.1016/j.cellimm.2018.10.004

69. Bhatelia K, Singh A, Tomar D, et al. Antiviral signaling protein MITA acts as a tumor suppressor in breast cancer by regulating NF-kappaB induced cell death. Biochim Biophys Acta. 2014;1842 (2):144-153. doi:10.1016/j.bbadis.2013.11.006

70. Tang $\mathrm{CH}$, Zundell JA, Ranatunga S, et al. Agonist-Mediated Activation of STING Induces Apoptosis in Malignant B Cells. Cancer Res. 2016;76(8):2137-2152. doi:10.1158/0008-5472. CAN-15-1885

71. An M, Yu C, Xi J, et al. Induction of necrotic cell death and activation of STING in the tumor microenvironment via cationic silica nanoparticles leading to enhanced antitumor immunity. Nanoscale. 2018;10(19):9311-9319. doi:10.1039/c8nr01376d

72. Li H, Zhuang Q, Wang Y, et al. HBV life cycle is restricted in mouse hepatocytes expressing human NTCP. Cell Mol Immunol. 2014;11(2):175-183. doi:10.1038/cmi.2013.66

73. Klionsky DJ, Abdelmohsen K, Abe A, et al. Guidelines for the use and interpretation of assays for monitoring autophagy (3rd edition). Autophagy. 2016;12(1):1-222. doi:10.1080/ 15548627.2015 .1100356

74. Liang D, Xiao-Feng H, Guan-Jun D, et al. Activated STING enhances Tregs infiltration in the HPV-related carcinogenesis of tongue squamous cells via the c-jun/CCL22 signal. Biochim Biophys Acta. 2015;1852(11):2494-2503. doi:10.1016/j. bbadis.2015.08.011

75. Li N, Zhou H, Wu H, et al. STING-IRF3 contributes to lipopolysaccharide-induced cardiac dysfunction, inflammation, apoptosis and pyroptosis by activating NLRP3. Redox Biol. 2019;24:101215. doi:10.1016/j.redox.2019.101215

76. Gaidt MM, Ebert TS, Chauhan D, et al. The DNA Inflammasome in human myeloid cells is initiated by a STING-Cell Death Program Upstream of NLRP3. Cell. 2017;171(5):1110-24 e18. doi:10.1016/j.cell.2017.09.039

77. Krzesniak M, Zajkowicz A, Gdowicz-Klosok A, et al. Synergistic activation of p53 by actinomycin D and nutlin-3a is associated with the upregulation of crucial regulators and effectors of innate immunity. Cell Signal. 2020;69:109552. doi:10.1016/j. cellsig.2020.109552

78. Gui X, Yang H, Li T, et al. Autophagy induction via STING trafficking is a primordial function of the cGAS pathway. Nature. 2019;567(7747):262-266. doi:10.1038/s41586-019-1006-9
79. Moretti J, Roy S, Bozec D, et al. STING Senses Microbial Viability to Orchestrate Stress-Mediated Autophagy of the Endoplasmic Reticulum. Cell. 2017;171(4):809-23 e13. doi:10.1016/j.cell.2017.09.034

80. Tan YS, Sansanaphongpricha K, Xie Y, et al. Mitigating SOX2-potentiated Immune Escape of Head and Neck Squamous Cell Carcinoma with a STING-inducing Nanosatellite Vaccine. Clin Cancer Res. 2018;24(17):4242-4255. doi:10.1158/10780432.CCR-17-2807

81. Demaria O, De Gassart A, Coso S, et al. STING activation of tumor endothelial cells initiates spontaneous and therapeutic antitumor immunity. Proc Natl Acad Sci U S A. 2015;112 (50):15408-15413. doi:10.1073/pnas.1512832112

82. Vogt D, Zaver S, Ranjan A, et al. STING is dispensable during KSHV infection of primary endothelial cells. Virology. 2020;540:150-159. doi:10.1016/j.virol.2019.11.012

83. Mao Y, Luo W, Zhang L, et al. STING-IRF3 triggers endothelial inflammation in response to free fatty acid-induced mitochondrial damage in diet-induced obesity. Arterioscler Thromb Vasc Biol. 2017;37(5):920-929. doi:10.1161/ATVBAHA.117.309017

84. Guo Y, Gu R, Gan D, et al. Mitochondrial DNA drives noncanonical inflammation activation via cGAS-STING signaling pathway in retinal microvascular endothelial cells. Cell Commun Signal. 2020;18(1):172. doi:10.1186/s12964-020-00637-3

85. Yuan L, Mao Y, Luo W, et al. Palmitic acid dysregulates the Hippo-YAP pathway and inhibits angiogenesis by inducing mitochondrial damage and activating the cytosolic DNA sensor cGAS-STING-IRF3 signaling mechanism. $J$ Biol Chem. 2017;292(36):15002-15015. doi:10.1074/jbc.M117.804005

86. Ishikawa $\mathrm{H}$, Ma Z, Barber GN. STING regulates intracellular DNA-mediated, type I interferon-dependent innate immunity. Nature. 2009;461(7265):788-792. doi:10.1038/nature08476

87. Liu Y, Jesus AA, Marrero B, et al. Activated STING in a vascular and pulmonary syndrome. $N$ Engl J Med. 2014;371(6):507-518. doi:10.1056/NEJMoa1312625

88. Warner JD, Irizarry-Caro RA, Bennion BG, et al. STING-associated vasculopathy develops independently of IRF3 in mice. $J$ Exp Med. 2017;214(11):3279-3292. doi:10.1084/jem.20171351

89. Ching LM, Cao Z, Kieda C, et al. Induction of endothelial cell apoptosis by the antivascular agent 5,6-Dimethylxanthenone4-acetic acid. $\mathrm{Br} J$ Cancer. 2002;86(12):1937-1942. doi:10.1038/sj.bjc. 6600368

90. Gao P, Ascano M, Zillinger T, et al. Structure-function analysis of STING activation by $\mathrm{c}\left[\mathrm{G}\left(2^{\prime}, 5^{\prime}\right) \mathrm{pA}\left(3^{\prime}, 5^{\prime}\right) \mathrm{p}\right]$ and targeting by antiviral DMXAA. Cell. 2013;154(4):748-762. doi:10.1016/j. cell.2013.07.023

91. Daei Farshchi Adli A, Jahanban-Esfahlan R, Seidi K, et al. An overview on Vadimezan (DMXAA): the vascular disrupting agent. Chem Biol Drug Des. 2018;91(5):996-1006. doi:10.1111/cbdd.13166

92. Yang H, Lee WS, Kong SJ, et al. STING activation reprograms tumor vasculatures and synergizes with VEGFR2 blockade. J Clin Invest. 2019;129(10):4350-4364. doi:10.1172/JCI125413

93. He L, Xiao X, Yang X, et al. STING signaling in tumorigenesis and cancer therapy: a friend or foe? Cancer Lett. 2017;402:203-212. doi:10.1016/j.canlet.2017.05.026

94. Chen Q, Boire A, Jin X, et al. Carcinoma-astrocyte gap junctions promote brain metastasis by cGAMP transfer. Nature. 2016;533 (7604):493-498. doi:10.1038/nature18268

95. Hou Y, Liang H, Rao E, et al. Non-canonical NF-kappaB Antagonizes STING Sensor-Mediated DNA Sensing in Radiotherapy. Immunity. 2018;49(3):490-503 e4. doi:10.1016/j. immuni.2018.07.008

96. Klarquist J, Hennies CM, Lehn MA, et al. STING-mediated DNA sensing promotes antitumor and autoimmune responses to dying cells $J$ Immunol. 2014;193(12):6124-6134. doi:10.4049/jimmunol.1 401869 
97. Munn DH, Mellor AL. IDO in the Tumor Microenvironment: inflammation, Counter-Regulation, and Tolerance. Trends Immunol. 2016;37(3):193-207. doi:10.1016/j.it.2016.01.002

98. Bakhoum SF, Ngo B, Laughney AM, et al. Chromosomal instability drives metastasis through a cytosolic DNA response. Nature. 2018;553(7689):467-472. doi:10.1038/nature25432

99. Xu X, Li M, Wu Z, et al. Endoplasmic Reticulum Transmembrane Proteins ZDHHC1 and STING Both Act as Direct Adaptors for IRF3 Activation in Teleost. J Immunol. 2017;199(10):3623-3633. doi:10.4049/jimmunol.1700750

100. Kranzusch PJ, Lee AS, Berger JM, et al. Structure of human cGAS reveals a conserved family of second-messenger enzymes in innate immunity. Cell Rep. 2013;3(5):1362-1368. doi:10.1016/ j.celrep.2013.05.008

101. Lv M, Chen M, Zhang R, et al. Manganese is critical for antitumor immune responses via cGAS-STING and improves the efficacy of clinical immunotherapy. Cell Res. 2020;30 (11):966-979. doi:10.1038/s41422-020-00395-4

102. Hou L, Tian C, Yan Y, et al. Manganese-based nanoactivator optimizes cancer immunotherapy via enhancing innate immunity. ACS Nano. 2020;14(4):3927-3940. doi:10.1021/ acsnano. $9 \mathrm{~b} 06111$

103. Wang M, Sooreshjani MA, Mikek C, et al. Suramin potently inhibits cGAMP synthase, cGAS, in THP1 cells to modulate IFN-beta levels. Future Med Chem. 2018;10(11):1301-1317. doi:10.4155/fmc-2017-0322

104. An J, Woodward JJ, Sasaki T, et al. Cutting edge: antimalarial drugs inhibit IFN-beta production through blockade of cyclic GMP-AMP synthase-DNA interaction. J Immunol. 2015;194 (9):4089-4093. doi:10.4049/jimmunol.1402793

105. Piscianz E, Cuzzoni E, Sharma R, et al. Reappraisal of Antimalarials in Interferonopathies: new Perspectives for Old Drugs. Curr Med Chem. 2018;25(24):2797-2810. doi:10.2174/ 0929867324666170911162331

106. Liu J, Wu X, Wang H, et al. HFE inhibits type I IFNs signaling by targeting the SQSTM1-mediated MAVS autophagic degradation. Autophagy. 2020:1-16. doi:10.1080/15548627.2020.1804683

107. Liu ZS, Cai H, Xue W, et al. G3BP1 promotes DNA binding and activation of cGAS. Nat Immunol. 2019;20(1):18-28. doi:10.1038/s41590-018-0262-4

108. Zhang CH, Wang JX, Cai ML, et al. The roles and mechanisms of G3BP1 in tumour promotion. J Drug Target. 2019;27 (3):300-305. doi:10.1080/1061186X.2018.1523415

109. Shim JH, Su ZY, Chae JI, et al. Epigallocatechin gallate suppresses lung cancer cell growth through Ras-GTPase-activating protein SH3 domain-binding protein 1. Cancer Prev Res. 2010;3 (5):670-679. doi:10.1158/1940-6207.CAPR-09-0185

110. Du XX, Su XD. Detection of Cyclic Dinucleotides by STING. Methods Mol Biol. 2017;1657:59-69. doi:10.1007/978-1-4939-7240-1 6

111. Burdette DL, Monroe KM, Sotelo-Troha K, et al. STING is a direct innate immune sensor of cyclic di-GMP. Nature. 2011;478(7370):515-518. doi:10.1038/nature10429

112. Sintim HO, Mikek CG, Wang M, et al. Interrupting cyclic dinucleotide-cGAS-STING axis with small molecules. Medchemcomm. 2019;10(12):1999-2023. doi:10.1039/c8md00555a

113. Konno H, Konno K, Barber GN. Cyclic dinucleotides trigger ULK1 (ATG1) phosphorylation of STING to prevent sustained innate immune signaling. Cell. 2013;155(3):688-698. doi:10.1016/j.cell.2013.09.049

114. Morehouse BR, Govande AA, Millman A, et al. STING cyclic dinucleotide sensing originated in bacteria. Nature. 2020;586 (7829):429-433. doi:10.1038/s41586-020-2719-5

115. Thomsen MK, Skouboe MK, Boularan C, et al. The cGAS-STING pathway is a therapeutic target in a preclinical model of hepatocellular carcinoma. Oncogene. 2020;39 (8):1652-1664. doi:10.1038/s41388-019-1108-8
116. Pollock AJ, Zaver SA, Woodward JJ. A STING-based biosensor affords broad cyclic dinucleotide detection within single living eukaryotic cells. Nat Commun. 2020;11(1):3533. doi:10.1038/ s41467-020-17228-y

117. Kwon Y, Park OJ, Kim J, et al. Cyclic Dinucleotides Inhibit Osteoclast Differentiation Through STING-Mediated Interferon-beta Signaling. $J$ Bone Miner Res. 2019;34 (7):1366-1375. doi:10.1002/jbmr.3701

118. Wu JJ, Zhao L, Hu HG, et al. Agonists and inhibitors of the STING pathway: potential agents for immunotherapy. Med Res Rev. 2020;40(3):1117-1141. doi:10.1002/med.21649

119. Liu H, Moura-Alves P, Pei G, et al. cGAS facilitates sensing of extracellular cyclic dinucleotides to activate innate immunity. EMBO Rep. 2019;20:4. doi:10.15252/embr.201846293

120. Cui J, Chen Y, Wang HY, et al. Mechanisms and pathways of innate immune activation and regulation in health and cancer. Hum Vaccin Immunother. 2014;10(11):3270-3285. doi:10.4161/ 21645515.2014.979640

121. Zhu Q, Man SM, Gurung P, et al. Cutting edge: STING mediates protection against colorectal tumorigenesis by governing the magnitude of intestinal inflammation. $J$ Immunol. 2014;193 (10):4779-4782. doi:10.4049/jimmunol.1402051

122. Leach DG, Dharmaraj N, Piotrowski SL, et al. STINGel: controlled release of a cyclic dinucleotide for enhanced cancer immunotherapy. Biomaterials. 2018;163:67-75. doi:10.1016/j. biomaterials.2018.01.035

123. Jenal U, Reinders A, Lori C. Cyclic di-GMP: second messenger extraordinaire. Nat Rev Microbiol. 2017;15(5):271-284. doi:10.1038/nrmicro. 2016.190

124. Guey B, Ablasser A. A carrier for cyclic dinucleotides. Nat Immunol. 2019;20(11):1418-1420. doi:10.1038/s41590-0190521-z

125. Berger G, Lawler SE. Novel non-nucleotidic STING agonists for cancer immunotherapy. Future Med Chem. 2018;10 (24):2767-2769. doi:10.4155/fmc-2018-0367

126. Curran E, Chen X, Corrales L, et al. STING Pathway Activation Stimulates Potent Immunity against Acute Myeloid Leukemia. Cell Rep. 2016;15(11):2357-2366. doi:10.1016/j. celrep.2016.05.023

127. Rauca VF, Licarete E, Luput L, et al. Combination therapy of simvastatin and 5, 6-dimethylxanthenone-4-acetic acid synergistically suppresses the aggressiveness of B16.F10 melanoma cells. PLoS One. 2018;13(8):e202827. doi:10.1371/journal.pone.020 2827

128. Smolarczyk R, Cichon T, Pilny E, et al. Author Correction: combination of anti-vascular agent - DMXAA and HIF-1alpha inhibitor - digoxin inhibits the growth of melanoma tumors. Sci Rep. 2020;10(1):5698. doi:10.1038/s41598-020-62440-x

129. Ahn J, Barber GN. Self-DNA, STING-dependent signaling and the origins of autoinflammatory disease. Curr Opin Immunol. 2014;31:121-126. doi:10.1016/j.coi.2014.10.009

130. Martin GR, Henare K, Salazar C, et al. Expression of a constitutively active human STING mutant in hematopoietic cells produces an Ifnar1-dependent vasculopathy in mice. Life Sci Alliance. 2019;2:3. doi:10.26508/1sa.201800215

131. Pokatayev V, Hasin N, Chon H, et al. RNase H2 catalytic core Aicardi-Goutieres syndrome-related mutant invokes cGAS-STING innate immune-sensing pathway in mice. $J$ Exp Med. 2016;213(3):329-336. doi:10.1084/jem.20151464

132. Haag SM, Gulen MF, Reymond L, et al. Targeting STING with covalent small-molecule inhibitors. Nature. 2018;559 (7713):269-273. doi:10.1038/s41586-018-0287-8

133. Le Naour J, Zitvogel L, Galluzzi L, et al. Trial watch: STING agonists in cancer therapy. Oncoimmunology. 2020;9(1):1777624. doi:10.1080/2162402X.2020.1777624 
134. Kwon J, Bakhoum SF. The Cytosolic DNA-Sensing cGAS-STING Pathway in Cancer. Cancer Discov. 2020;10 (1):26-39. doi:10.1158/2159-8290.CD-19-0761

135. Jiang $M$, Chen $P$, Wang $L$, et al. cGAS-STING, an important pathway in cancer immunotherapy. J Hematol Oncol. 2020;13 (1):81. doi:10.1186/s13045-020-00916-z

136. Li A, Yi M, Qin S, et al. Activating cGAS-STING pathway for the optimal effect of cancer immunotherapy. J Hematol Oncol. 2019;12(1):35. doi:10.1186/s13045-019-0721-x

137. Khoo LT, Chen LY. Role of the cGAS-STING pathway in cancer development and oncotherapeutic approaches. EMBO Rep. 2018;19:12. doi:10.15252/embr.201846935

138. Iurescia S, Fioretti D, Rinaldi M. Targeting Cytosolic Nucleic Acid-Sensing Pathways for Cancer Immunotherapies. Front Immunol. 2018;9:711. doi:10.3389/fimmu.2018.00711

139. Lara PN Jr, Douillard JY, Nakagawa K, et al. Randomized Phase III placebo-controlled trial of carboplatin and paclitaxel with or without the vascular disrupting agent vadimezan (ASA404) in advanced non-small-cell lung cancer. J Clin Oncol. 2011;29 (22):2965-2971. doi:10.1200/JCO.2011.35.0660

140. McKeage MJ. Clinical trials of vascular disrupting agents in advanced non-small-cell lung cancer. Clin Lung Cancer. 2011;12(3):143-147. doi:10.1016/j.cllc.2011.03.010

141. Pan BS, Perera SA, Piesvaux JA, et al. An orally available non-nucleotide STING agonist with antitumor activity. Science. 2020;369(6506):eaba6098. doi:10.1126/science.aba6098

142. Chin EN, Yu C, Vartabedian VF, et al. Antitumor activity of a systemic STING-activating non-nucleotide cGAMP mimetic. Science. 2020;369(6506):993-999. doi:10.1126/science.abb4255

143. Foote JB, Kok M, Leatherman JM, et al. A STING Agonist Given with OX40 Receptor and PD-L1 modulators primes immunity and reduces tumor growth in tolerized mice. Cancer Immunol Res. 2017;5(6):468-479. doi:10.1158/2326-6066.CIR-16-0284

144. Flood BA, Higgs EF, Li S, et al. STING pathway agonism as a cancer therapeutic. Immunol Rev. 2019;290(1):24-38. doi:10.1111/imr.12765

145. Venkatesulu BP, Mallick S, Lin SH, et al. A systematic review of the influence of radiation-induced lymphopenia on survival outcomes in solid tumors. Crit Rev Oncol Hematol. 2018;123:42-51. doi:10.1016/j.critrevonc.2018.01.003

146. Mackenzie KJ, Carroll P, Martin CA, et al. cGAS surveillance of micronuclei links genome instability to innate immunity. Nature. 2017;548(7668):461-465. doi:10.1038/nature23449

147. Harding SM, Benci JL, Irianto J, et al. Mitotic progression following DNA damage enables pattern recognition within micronuclei. Nature. 2017;548(7668):466-470. doi:10.1038/ nature 23470

148. Baird JR, Friedman D, Cottam B, et al. Radiotherapy Combined with Novel STING-Targeting Oligonucleotides Results in Regression of Established Tumors. Cancer Res. 2016;76 (1):50-61. doi:10.1158/0008-5472.CAN-14-3619

149. Wang QT, Nie Y, Sun SN, et al. Tumor-associated antigen-based personalized dendritic cell vaccine in solid tumor patients. Cancer Immunol Immunother. 2020;69(7):1375-1387. doi:10.1007/ s00262-020-02496-w

150. He Y, Zhao H, Li XM, et al. Use of mesothelin as a tumor-associated antigen in cervical squamous cell carcinoma. Gene. 2019;690:30-37. doi:10.1016/j.gene.2018.12.029

151. Costa-Nunes C, Cachot A, Bobisse S, et al. High-throughput screening of human tumor antigen-specific CD4 T cells, including neoantigen-reactive $\mathrm{T}$ Cells. Clin Cancer Res. 2019;25 (14):4320-4331. doi:10.1158/1078-0432.CCR-18-1356

152. Kinkead HL, Hopkins A, Lutz E, et al. Combining STING-based neoantigen-targeted vaccine with checkpoint modulators enhances antitumor immunity in murine pancreatic cancer. JCI Insight. 2018;3:20. doi:10.1172/jci.insight. 122857
153. Wang Z, Celis E. STING activator c-di-GMP enhances the anti-tumor effects of peptide vaccines in melanoma-bearing mice. Cancer Immunol Immunother. 2015;64(8):1057-1066. doi:10.1007/s00262-015-1713-5

154. Topalian SL, Drake CG, Pardoll DM. Immune checkpoint blockade: a common denominator approach to cancer therapy. Cancer Cell. 2015;27(4):450-461. doi:10.1016/j.ccell.2015.03.001

155. Postow MA, Sidlow R, Hellmann MD. Immune-Related Adverse Events Associated with Immune Checkpoint Blockade. $N$ Engl $J$ Med. 2018;378(2):158-168. doi:10.1056/NEJMra1703481

156. Keenan TE, Burke KP, Van Allen EM. Genomic correlates of response to immune checkpoint blockade. Nat Med. 2019;25 (3):389-402. doi:10.1038/s41591-019-0382-x

157. McGranahan N, Furness AJ, Rosenthal R, et al. Clonal neoantigens elicit $\mathrm{T}$ cell immunoreactivity and sensitivity to immune checkpoint blockade. Science. 2016;351(6280):1463-1469. doi:10.1126/science.aaf1490

158. Li B, Chan HL, Chen P. Immune checkpoint inhibitors: basics and challenges. Curr Med Chem. 2019;26(17):3009-3025. doi:10.2174/0929867324666170804143706

159. Minn AJ, Wherry EJ. Combination Cancer Therapies with Immune Checkpoint Blockade: convergence on Interferon Signaling. Cell. 2016;165(2):272-275. doi:10.1016/j. cell.2016.03.031

160. Wei SC, Duffy CR, Allison JP. Fundamental Mechanisms of Immune Checkpoint Blockade Therapy. Cancer Discov. 2018;8 (9):1069-1086. doi:10.1158/2159-8290.CD-18-0367

161. Ribas A, Wolchok JD. Cancer immunotherapy using checkpoint blockade. Science. 2018;359(6382):1350-1355. doi:10.1126/ science.aar4060

162. Benci JL, Johnson LR, Choa R, et al. Opposing functions of interferon coordinate adaptive and innate immune responses to cancer immune checkpoint blockade. Cell. 2019;178(4):933-48 e14. doi:10.1016/j.cell.2019.07.019

163. Parkes EE, Walker SM, Taggart LE, et al. Activation of STING-dependent innate immune signaling by s-phase-specific dna damage in breast cancer. J Natl Cancer Inst. 2017;109:1. doi:10.1093/jnci/djw199

164. Wang $\mathrm{H}, \mathrm{Hu} \mathrm{S}$, Chen $\mathrm{X}$, et al. cGAS is essential for the antitumor effect of immune checkpoint blockade. Proc Natl Acad Sci U S A. 2017;114(7):1637-1642. doi:10.1073/pnas.1621363114

165. Wilson DR, Sen R, Sunshine JC, et al. Biodegradable STING agonist nanoparticles for enhanced cancer immunotherapy. Nanomedicine. 2018;14(2):237-246. doi:10.1016/j. nano.2017.10.013

166. Ma S, Li X, Wang X, et al. Current Progress in CAR-T Cell Therapy for Solid Tumors. Int $J$ Biol Sci. 2019;15 (12):2548-2560. doi:10.7150/ijbs.34213

167. Majzner RG, Mackall CL. Tumor Antigen Escape from CAR T-cell Therapy. Cancer Discov. 2018;8(10):1219-1226. doi:10.1158/2159-8290.CD-18-0442

168. Wei J, Han X, Bo J, et al. Target selection for CAR-T therapy. J Hematol Oncol. 2019;12(1):62. doi:10.1186/s13045-019-0758-x

169. Minn I, Rowe SP, Pomper MG. Enhancing CAR T-cell therapy through cellular imaging and radiotherapy. Lancet Oncol. 2019;20 (8):e443-e51. doi:10.1016/S1470-2045(19)30461-9

170. Wang Z, Wu Z, Liu Y, et al. New development in CAR-T cell therapy. J Hematol Oncol. 2017;10(1):53. doi:10.1186/s13045017-0423-1

171. Smith TT, Moffett HF, Stephan SB, et al. Biopolymers codelivering engineered T cells and STING agonists can eliminate heterogeneous tumors. J Clin Invest. 2017;127(6):2176-2191. doi:10.1172/JCI87624 


\section{Publish your work in this journal}

OncoTargets and Therapy is an international, peer-reviewed, open access journal focusing on the pathological basis of all cancers, potential targets for therapy and treatment protocols employed to improve the management of cancer patients. The journal also focuses on the impact of management programs and new therapeutic agents and protocols on patient perspectives such as quality of life, adherence and satisfaction. The manuscript management system is completely online and includes a very quick and fair peer-review system, which is all easy to use. Visit http://www.dovepress.com/ testimonials.php to read real quotes from published authors.

Submit your manuscript here: https://www.dovepress.com/oncotargets-and-therapy-journal 